\title{
Pursuit eye movements: A review
}

\author{
R Hansraj*
}

Discipline of Optometry, University of Kwa Zulu-Natal, Westville Campus, Private Bag X54001, Durban, 4000 South Africa

*<hansrajr@ukzn.ac.za>

Received 29 July 2008; revised version accepted 9 December 2008

Visual and ocular health is not limited to refractive error and retinal pathology. Even in the absence of any refractive error or retinal pathology, to see an object, with the best resolution and clarity, it has to be imaged on the fovea. This alignment of the foveas towards the targets of visual interest is brought about by eye movements, including pursuits and saccades ${ }^{1-4}$. Without these movements, or in the event of dysfunctional eye movements, good vision cannot be assured, stereopsis would be reduced and stabilization of vision during locomotion would not occur ${ }^{1,5}$. Dysfunctional eye movements also serve as indicators of extraocular muscle integrity, cranial nerve or supranuclear gaze centre abnormalities and central nervous system disorders ${ }^{6,7}$. Hence, it is important that ocular motility testing, the simplest techniques involving the assessment of pursuit and saccades, be part of the routine eye examination. However, it also requires that the practitioner be able to perform the technique adequately, identify abnormalities and understand their implications. Even though smooth pursuit movements provide poor site-lesion localiszation, it the most sensitive to pathology of all the ocular motor tests ${ }^{8}$. This article therefore revisits this area of vision and provides a brief review of pursuit eye movements.

\section{Description}

Pursuits are smooth tracking movements which maintain foveal fixation when viewing a moving object and hence stabilize the retinal image ${ }^{2,9,10}$. They therefore aim to match eye velocity with target velocity and thus enable continuous clear vision of moving objects $4,7,11$. They are slower movements generally less than $40^{\circ}$ /sec but the reaction time is about 125 msec $^{1}$. Faster target velocities will result in the pursuit movement being accompanied by catch-up saccades $^{7}$. Pursuit eye movements play an important role in driving and sports ${ }^{11}$. Pursuit dysfunction is therefore more likely to interfere with sport activities and may cause symptoms such as trouble catching and hitting a baseball and difficulty with other sports involving timing and following a moving object ${ }^{11}$.

\section{Neural control}

The stimulus for pursuits is motion of an object, hence the neural pathway originates in the primary visual cortex, more specifically the peristriate cortex of the occipital motor area, also known as Brodman's area 19 or area V1.4, 7, 12 Projections are then sent to the extrastriatal V5 which includes the middle temporal (MT) and medial superior temporal (MST) areas which lie in the superior temporal sulcus ${ }^{4,13}$. In this area it is not the individual muscles, but rather movement, that is represented ${ }^{5}$. The MT is responsible for pursuit initiation and the MST is responsible for pursuit maintenance, and both these areas therefore serve as the centre for motion processing ${ }^{3,12,14}$. Cells in the MST fire in response to movement of the head, and the target, as pursuits must track targets that do not always move on the retina. Each hemisphere of the MST codes motion to the ipsilateral side, that is, stimulation of the right MST causes a rightward following eye movement ${ }^{1,11}$. Thus information regarding the direction and speed of movement of a target is processed in these areas ${ }^{15}$. The signals are then sent to the frontal eye fields where the command for generation of the pursuit movement occurs ${ }^{4}$. With respect to 
the frontal eye fields, the area around the precentral gyrus that is responsible for pursuit generation is located slightly more inferior and lateral to that area involved in the generation of saccadic eye movement ${ }^{14}$. The frontal eye fields are also involved in voluntary pursuits which do not rely on a moving stimulus ${ }^{15}$.

The fibres, for both horizontal and vertical pursuits then descend through the internal capsule as part of the pyramidal tract, and just above the level of the sixth nerve nuclei they cross over to the opposite side of the brain stem ${ }^{5}$. They eventually end in "pontine centre" for lateral gaze in the region of the dorsal lat-

\section{PERISTRIATE CORTEX}

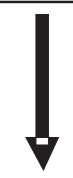

\section{DORSAL LATERAL PONTINE NUCLEUS}

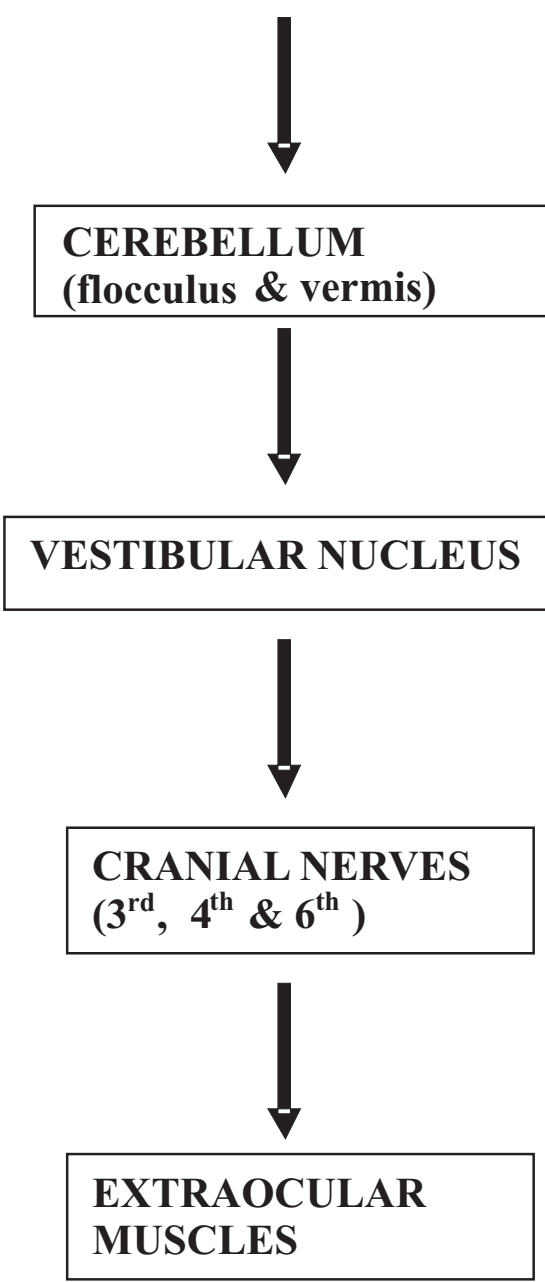

Figure 1: Overall neural control of pursuit eye movements eral pontine nucleus (DLPN) ${ }^{5,15}$. Velocity signals are projected from here to the floccular region and to the vermis lobules of the cerebellum ${ }^{12,13}$. The flocculus is thought to maintain pursuit during steady constant tracking while the vermis is important when the target velocity changes or when initiating pursuit ${ }^{15}$. The role of the cerebellum is to sort out eye and head rotations in the tracking process and to sort out the ocular pursuit signal from visual and eye-head motor inputs. From here the activity passes via parts of the vestibular nucleus (VN) which performs the necessary integration of the velocity signal to position signal that is sent to the eye muscle motorneurons. The last part involves the fibres running through the medial longitudinal fasiculus to either the third, fourth and sixth cranial nerve nuclei and finally to the relevant extraocular muscles via the respective cranial nerves ${ }^{4,5,7}$. This neural control is summarized in Figure 1.

\section{Clinical Testing}

Clinical testing of pursuit eye movements should involve the observation of whether the pursuits are smooth or jerky, and if there are any restrictions in gaze $^{7}$. The patient removes their spectacles so that the examiner can easily view the eyes and their alignment ${ }^{16}$. The examiner should stand or sit facing the patient at a distance of approximately $1 \mathrm{~m}$. The target could be a Woolf ball, or preferably a penlight which allows the corneal reflexes to be observed as well ${ }^{17}$. Observation of the corneal reflexes during the assessment of smooth pursuits provides an objective method for observing ocular alignment ${ }^{18}$. For paediatric patients a small finger puppet or other colorful target which will ensure attention may be used ${ }^{16}$. The target is held approximately $40 \mathrm{~cm}$ from the midpoint between the patient's eyes but the distance may be anywhere between $30-50 \mathrm{~cm}$ so long as the examiner can lift the lids or control the head posture with the non-dominant hand for better observation of the eyes if required. ${ }^{16,19,20}$ The examiner instructs the patient to keep both eyes open, and to follow the target as it moves. The target is moved through the broad $\mathrm{H}$ pattern which assesses the eyes in the diagnostic action fields of the six extraocular muscles as is depicted in Figure 2. ${ }^{16,20}$ The examiner should ensure that the target is taken to the maximum extent until they are no longer able to follow it, for example, when assess- 
ing right lateral gaze, move the target to the extreme right along the midline until no sclera can be seen both temporally in the right eye and medially in the left eye ${ }^{21}$. It is normal to see an endpoint nystagmus when the eyes are in the extreme position, however, the endpoint nystagmus may sometimes be accentuated by paresis of one or more of the extraocular muscles to which the examiner must be alert ${ }^{16,21}$.

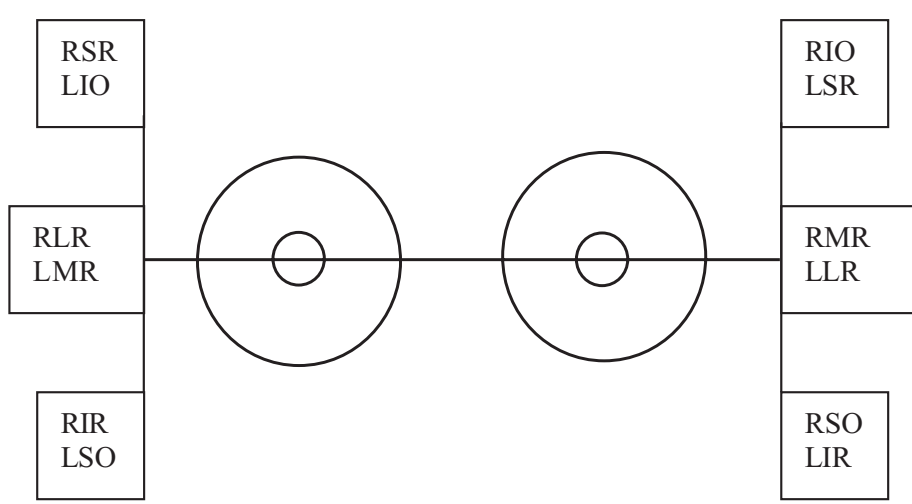

Figure 2: ' $\mathrm{H}$ ' pattern of assessing pursuit eye movements

The patient is asked to report any discomfort or diplopia of the target which can be an indication of muscle paresis ${ }^{17,19}$. If diplopia does occur, the examiner should determine whether it is horizontal or vertical which also allows the examiner to isolate the muscles that may be involved ${ }^{20}$. In the absence of an anomaly, the pursuit movements of the eyes should appear smooth and allow accurate fixation and tracking of the target in all positions of gaze. The acronym for this 'Full, Smooth and Accurate' movement is 'FSA'. Any failures of extraocular muscle action, or abnormalities such as accentuated nystagmus should be recorded. According to Jampolsky's scale, underactions are recorded with negative integers $(-1$ through -4 ), and overactions with positive numbers, with a 1 indicating a slight reduction and 4 indicating that the eye would not move past the midline ${ }^{19}$. It is normal, however, to note jerky pursuit movements with midline jumps, in children under 6 years old ${ }^{21}$. Watch the eyes carefully also for the use of catch-up saccades when the pursuit movements are very slow and the eye is unable to match the target velocity ${ }^{7}$.

Binocular testing should be followed with monocular testing if a restriction of version movement was detected ${ }^{17}$. Monocular testing will then allow for the determination of whether the underaction detected during binocular testing was due to a mechanical re- striction $^{19}$. An underaction that is more or less equal in both binocular and monocular testing may be indicative of a mechanical restriction and may require forced duction testing ${ }^{19}$.

\section{Lesions}

Smooth pursuit movements can reflect among others, the psychological state of a person, and the presence of pathology in the central nervous sys-

tem $^{10,22,23}$. Abnormal pursuit eye movements have been reported in schizophrenic patients including poor pursuit velocity and initiation ${ }^{24}$. These abnormal pursuits in schizophrenic patients have been related to greater activity of the hippocampus and the inability to inhibit the saccadic system when performing a pursuit movement resulting in the intrusion of saccades when attempting to do a pursuit ${ }^{25}$.

Damage to the frontal and/or parietal lobe will result in the patient having difficulty performing pursuits to the same side as the lesion and thus is called asymmetrical pursuits which tend to be transient ${ }^{26}$. However, this type of asymmetrical pursuit tends to persist for only a few weeks ${ }^{26}$. In certain conditions like myotonic dystrophy, lesions in the frontal lobe are more permanent and hence so too are the defects in pursuits ${ }^{27}$. Bilateral occipital lobe lesions will result in a complete loss of smooth pursuit movements, as well as, with corresponding visual field defects ${ }^{15,28}$ Poor pursuit movements have also been recorded in amblyopic patients and has attributed to the poor development of the binocular cells of the visual cortex in the occipital lobe ${ }^{29}$.

On the other hand, a smooth version in one direction, with a cogwheeling, step-like pursuit in the other direction is suggestive of parietal lobe disease $\mathrm{e}^{21}$. Often the pursuit movement is affected towards the side of the affected lobe ${ }^{30}$. These patients can therefore also present with homonymous field defects, and conjugate deviation of the eyes, that is, during forced closure the eyes will tend to deviate away from the side of the parietal lesion ${ }^{30}$. The eyes are observed to drift in the direction of the intact hemisphere ${ }^{31}$. In some patients with poor peripheral vision, 'disorganized' pursuits are observed as the eyes get lost during tracking and they thus exhibit searching saccades ${ }^{26}$. Parietal lobe lesions may be caused by gliomas, metastases or stroke in the middle cerebral artery ${ }^{30}$. 
Parinaud's syndrome is a condition which results from a lesion in the dorsal midbrain area ${ }^{32}$. Some of the causes include pineal gland lesions, multiple sclerosis and vascular diseases ${ }^{33}$. Being a syndrome it will present with defective vertical pursuits more especially on upgaze, together with a loss of convergence, mydriasis and loss of the pupillary light reflex $^{6,32}$. If there is a loss of upward gaze together with fixed dilated pupils, then the lesion is most often at the level of the superior colliculus ${ }^{33}$. These patients may present with a retraction nystagmus which presents as an inward and outward movement of both the eyes when attempting upward gaze ${ }^{33}$. Inferior colliculus lesions present more with a loss of downward gaze, normal pupillary reactions and a loss of convergence ${ }^{33}$.

The most common abnormality affecting pursuits is cogwheeling which are step-like eye movements, (saccades), that are used instead of smooth pursuits when following an object ${ }^{11,18}$. The causes are nu- merous and may include basal ganglia disease for example Parkinson's or cerebellar disease, fatigue and inattention ${ }^{11,18,21}$. This is observed in a progressive supranuclear palsy also referred to as the Steele-Richardson-Olszewski syndrome ${ }^{33}$. In this syndrome vertical gaze is affected in the early stages with a particular impairment on downward gaze. Other signs include increased rigidity, dysarthria and dementia hence the link to Parkinson's disease ${ }^{33}$. As the disease progresses, the horizontal pursuits are affected as well and become cogwheel ${ }^{33}$.

The sixth nerve nucleus acts as a final common pathway for horizontal gaze as is depicted in Figure 3. ${ }^{34,35}$ Therefore, any lesion between the pre-motor and motor nuclei, called an ophthalmoplegia, can also be detected during pursuit testing. The lesions occur due to the neural connection between the sixth nerve nuclei, third nerve nuclei and the medial and lateral rectus muscles. The type of ophthalmoplegia will depend on the location of the lesion.

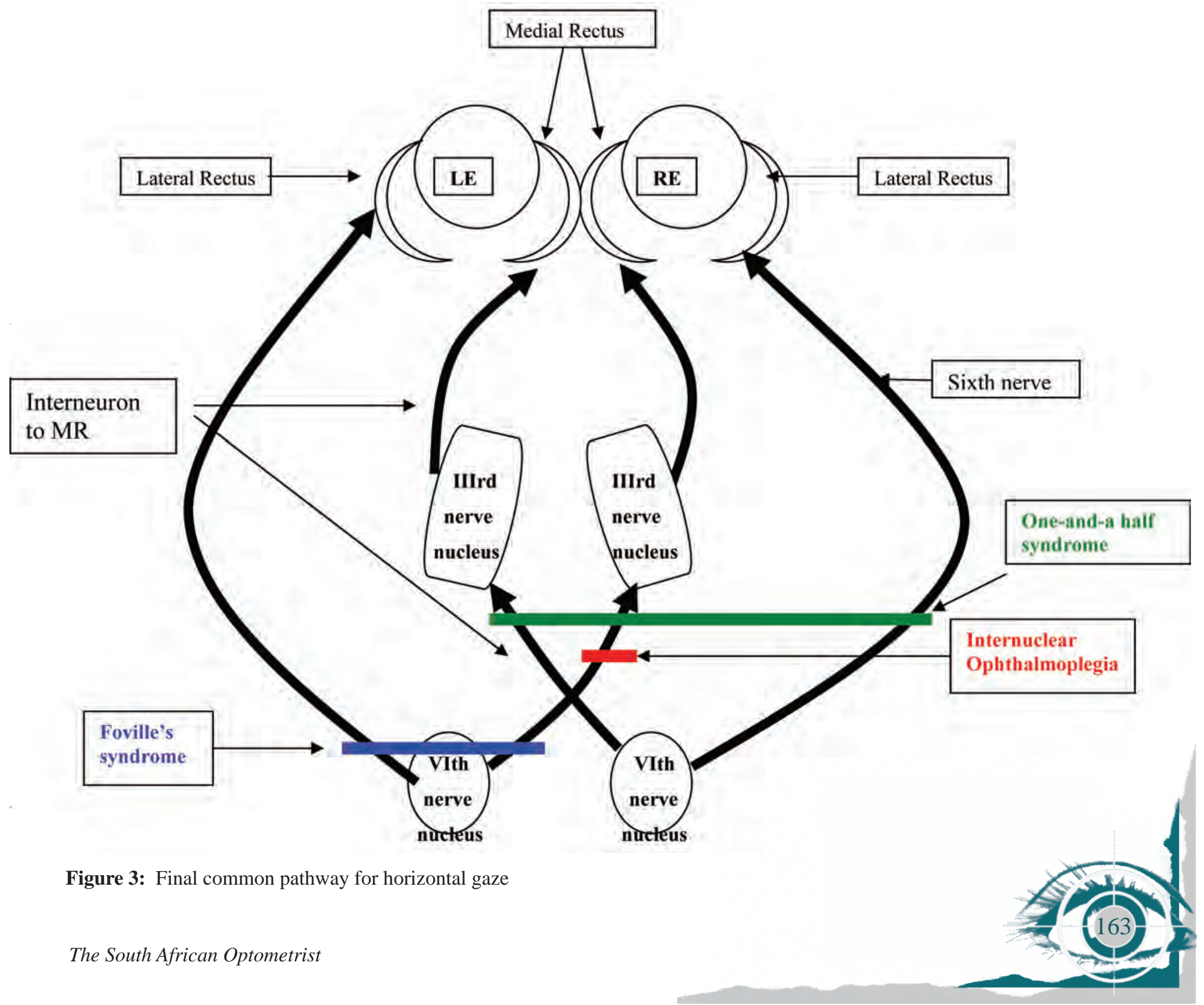


The most common of these is an internuclear ophthalmoplegia (INO) which occurs due to a disruption of the interneuron pathway, anteriorly or midway, from the sixth nerve nuclei to the motor neuron nuclei of the third nerve $e^{5,33,34}$. The affected eye is unable to move to the contralateral side on lateral gaze and thus the eye drifts temporalward and may develop an exodeviation. Patients therefore tend to commonly complain of horizontal diplopia due to the induced exodeviation $^{36}$. However, convergence is normal in these patients which distinguishes it from a disruption of the abducens nucleus. The cause of this INO is often multiple sclerosis in young adults or may be due to occlusion of the basilar artery ${ }^{33}$. In older patients, INO has been related more often to ischemic vascular diseases, neoplasms and inflammation of the brainstem $^{33}$.

If the lesion was more posterior, then it affects both the interneuron to the third nerve nuclei and the sixth nerve to the ipsilateral lateral rectus. This results in failure of lateral gaze of both eyes to the side of the lesion which is also known as conjugate gaze palsy. If the lesion is bilateral, then the patient will not be above to move the left eye beyond the midline on right gaze, and the right eye beyond the midline of left gaze, however, convergence will be normal indicating that this is not a problem of the medial rectii muscles $^{5}$. Technically this condition it is referred to as Foville's syndrome or posterior internuclear ophthalmoloplegia. As it is a syndrome other findings include contralateral limb paralysis and ipsilateral facial paralysis. This is occurs due ipsilateral fifth, seventh and eight nerve palsies together with a Horner's syndrome ${ }^{33}$.

If the lesion affects the sixth nerve nucleus and both the interneurons, then the ipsilateral eye is immovable during lateral gaze, and there is failure of adduction of the contralateral eye. This condition is hence referred to as the 'One-and-a-half' syndrome $^{6,34}$. It is usually caused by a unilateral lesion of the paramedian pontine reticular formation or the abducens nucleus ${ }^{37}$. This syndrome is thus sometimes referred to as paralytic pontine exotropia, when in primary position the eye opposite the side of the lesion is exotropic while the eye on the same side as the lesion tends to remain straight ahead ${ }^{33,38}$.

Pursuits may be also be affected by age, attention and motivation ${ }^{7}, 11,39$. The pursuit movement task can be performed very poorly in an inattentive patient who does not have any form of central lesion or a target that does not hold the patient's attention ${ }^{15,26}$. Degraded pursuits are occasionally found in young adults and more often in older subjects ${ }^{7}$ and should alert the clinician to Alzheimer's disease, Parkinson's disease and degenerative changes in the cerebellum which will degrade the pursuit movement ${ }^{23,40}$. Drugs such as alcohol, barbiturates, benzodiazepines and tobacco can also adversely affect the pursuit system and result in fragmented pursuits that could be slow or jerky $6,7,15,41$.

\section{Conclusion}

Visual well-being is more than just being able to see the 6/6 visual acuity line and having no sight-threatening conditions. It also requires eye movements intricately programmed at various levels, to ensure that the stimulus of light from the object of regard is received by the fovea. In this way visual appreciation of the world is optimized. Optometrists are often consulted first by patients having vision problems and it is therefore imperative that they are able to diagnose any visual problem and make timeous referrals. This will require that the visual examination conducted is comprehensive and assesses all aspects of vision. Often, in the current commercially driven private health sector, certain integral tests are being left out for example the assessment of eye movements. Pursuit eye movements can be assessed clinically using simple techniques and inexpensive equipment, and yet it can provide very important clinical information that may not only pertain directly to the eyes, but also reflect the integrity of the central nervous system. It is therefore important that practitioners incorporate this simple test, but very useful test into their clinical routine.

\section{References}

1. Thamburaj, K. Ocular Movements. http://www.thamburaj.com/ocular_movements.htm. 2006. Date accessed: 5/06/2008.

2. Fukushima J, Akao T, Kurkin S, Kaneko CRS, Fukushima K. The vestibular-related frontal cortex and its role in smoothpursuit eye movements and vestibular-pursuit interactions. J Vestib Res 200616 1-22.

3. Ilg UJ. The role of areas MT and MST in coding of visual motion underlying the execution of smooth pursuit. Vision Res 200848 2062-2069. 
4. Lencer R, Trillenberg P. Neurophysiology and neuroanatomy of smooth pursuit in humans. Brain Cogn 2008 (Article in press Accessed 9th October 2008).

5. Adler FH. Textbook of Ophthalmology. Philadelphia: WB Saunders Company, 1962.

6. Larkin G, Elston J, Bain PG. Disorders of ocular motility. Br J Optom Disp 1995 5-11.

7. Workfolk, R. The control of eye movements. Optom Today October 1992 26-29.

8. Katz J, Burkard RF, Medwetsky L. Handbook of Clinical Audiology Philadelphia: Lippincott Williams \& Wilkins 2001.

9. McIlwain, JT (ed). An Introduction to the Biology of Vision. Rhode Island: Cambridge University Press, 1996.

10. Bozhkova VP, Surovicheva NS, Nikolaev DP, Lebedev DG. Characteristics of smooth pursuit in children and adults in apparent motion tests. Hum Physio 200834 405-412.

11. Scheiman M and Wick B. Clinical Management of Binocular Vision. Philadelphia : JP Lippincott Company, 1994.

12. Krauzlis RJ. Recasting the smooth pursuit eye movement system. J Neurophysiol 200491 591-603.

13. Nagel M, Sprenger A, Hohagen F, Binkofski F, Lencer R. Cortical mechanisms of retinal and extraretinal smooth pursuit eye movements to different target velocities. Neuro Image 200841 483-492.

14. Petit L, Haxby JV. Functional anatomy of pursuit eye movements in humans as revealed by fMRI. J Neurophysiol 199982 463-471.

15. Brazis PW, Masdeu JC, Biller J. Localization in Clinical Neurology. Philadelphia: Lippincott William \& Wilkins 2006.

16. Benjamin, WJ (ed) Borish's Clinical Refraction. Philadelphia: WB Saunders Company, 1998.

17. Roberson G. The extraocular muscles, Part two, examination and assessment. Optician 1996212 24-30.

18. Campbell WW, DeJong RN, Haerer AF. DeJong's the Neurologic Examination : Incorporating the Fundamentals of Neuroanatomy and Neurophysiology Philadelphia : Lippincott Williams \& Wilkins 2005.

19. Zadnik, K. The Ocular Examination - Measurements and Findings. Philadelphia: WB Saunders Company, 1997.

20. Elliot DB. Clinical Procedures in Primary Eye Care. Oxford: Butterworth Heinemann, 1997.

21. Eskridge, JB, Amos, JF, Bartlett, JD. Clinical Procedures in Optometry. New York: JB Lippincott Company, 1991.

22. Rommelse NNJ, Van der Stigchel S, Sergeant JA. A review on eye movement studies in childhood and adolescent psychiatry. Brain Cogn 2008 (Article in press Accessed 20th October 2008).

23. Garbutt S, Matlin A, Hellmuth J, Schenk AK, Johnson JK, Rosen H, Dean D, Kramer J, Neuhaus J, Miller BL, Lisberger SG, Boxer AL. Oculomotor function in frontotemporal lobar degeneration, related disorders and Alzheimer's disease. Brain 2008131 1268-1281.

24. Hong LE, Turano KA, O’Neill H, Hao L, Wonodi I, McMahon RP, Elliott A, Thaker GK. Refining the predictive pursuit endophenotype in schizophrenia. Biol Psychiat 2008 63 458-464.
25. Tregellas JR, Tanabe JL, Miller DE, Ross RG, Olincy A, Freedman R. Neurobiology of smooth pursuit eye movement deficits in schizophrenia: An fMRI study. Am J Psychiatry 2004161 315-321.

26. Jacobson GP, Newman CW, Karthush JM (eds). Handbook of Balance Function Testing. St Louis: Mosby-Year Book, Inc. 1993.

27. Kimmig H, Petrick M, Orszagh M, Mergner T. Role of anterior and occipital white matter lesions for smooth eye tracking in myotonic dystrophy. J Neurol Neurosur Ps 200272 808-811 .

28. Miller NR, Walsh FB, Hoyt WF, Newman NJ, Biousse V, Kerrison JB. Walsh and Hoyt's Clinical Neuro-Ophthalmology: The Essentials. Philadelphia: Lippincott Williams \& Wilkins 2007.

29. Prakash P, Grover AK, Khosla PK, Gahlot DK. Ocular motility in amblyopic and the fellow eye. Indian J Ophthal. 198230 531-538.

30. Lee DA, Higginbotham EJ. Clinical Guide to Comprehensive Ophthalmology. New York: Thieme. 1999.

31. Pryse-Phillips W. Companion to Clinical Neurology. New York: Oxford University Press 2003.

32. Wilhelm BJ, Wilhelm H, Moro S, Barbur JL. Pupil response components: studies in patients with Parinaud's syndrome. Brain 2002125 2296-2307.

33. Agarwal A. Handbook of Ophthalmology. SLACK Incorporated: Thorofare, NJ. 2006.

34. Savino PJ, Danesh-Meyer H. Neuro-ophthalmology: Color Atlas and Synopsis of Clinical Ophthalmology. New York: McGraw Hill, 2003.

35. Loewenstein JI, Lee S. Ophthalmology: Just the facts. New York: McGraw Hill, 2004.

36. Riordan-Eva P, Whitcher JP, Vaughan D, Asbury T. Vaughan \& Asbury's General Ophthalmology. New York : McGrawHill Medical Publishers 2007.

37. Wall M, Wray SH. The one-and-a-half syndrome-A unilateral disorder of the pontine tegmentum. Neurology 1983 33971.

38. Anderson CA, Sandberg E, Filley CM, Harris SL, Tyler KL. One and One-half Syndrome with supranuclear facial weakness. Arch Neurol 199956 1509-1511.

39. Roberson G. The extraocular muscles, Part One, Anatomy, histology and physiology. Optician 1996212 22-27.

40. Lekwuwa, GU, Barnes GR, Collins CJS, Limousin P. Progressive bradykinesia and hypokinesia of ocular pursuit in Parkinson's disease. J Neurol Neurosur Ps 199966 746753.

41. Hutton S, Crawford T, Gibbins H, Cuthbert I, Kennard C, Joyce E. Short and long term effects of antipsychotic medication on smooth pursuit eye tracking in schizophrenia. Psychopharmacology 2001157 284-291. 